\title{
Análise de percepções de estudantes de licenciatura em matemática frente a respostas a uma tarefa sobre o conceito de Equação Modular
}

\author{
Daniela Mendes Vieira Silva \\ Mara Jane Neves Lima Freire \\ Daniel de Oliveira Lima
}

\section{Resumo}

O presente artigo apresenta reflexões sobre produções escritas de licenciandos sobre uma tarefa envolvendo o conceito de Equação Modular. A metodologia de aplicação envolveu a entrega da referida tarefa e de um questionário a licenciandos. Os participantes foram convidados a analisar a tarefa recebida e a responder ao questionário proposto. As respostas dos estudantes foram analisadas dentro do Modelo de Toulmin, adaptado por Biza e Nardi (2009), a partir desta análise chegamos às conclusões de que os licenciandos, de uma maneira geral, apresentam soluções diretas como forma de explicar uma questão, assim como também da forte presença observada das suas experiências, enquanto estudantes da educação básica, com esta mesma prática por parte de seus professores. Tal percepção nos remete ao problema da dupla descontinuidade observada por Felix Klein (2009). Tanto a abordagem direta enquanto licenciandos quanto à memória dela, enquanto estudantes da educação básica do passado, estão atreladas às ideias muito gerais das abordagens pedagógicas apresentadas pelos participantes da oficina. Portanto, atividades como esta, que permitem uma reflexão sobre a própria prática, se mostram como uma oportunidade para a discussão e desenvolvimento pedagógico/matemático/didático, uma vez que elas ensejam o autoconhecimento não só daqueles que a vivenciam, mas também permite a compreensão, por parte daqueles que a aplicam, sobre as complexas relações entre diferentes campos do saber que interferem na prática matemática em sala de aula.

Palavras-chave: Equação Modular. Formação inicial de professores. 


\title{
Analysis of the perceptions of undergraduate students in mathematics in response to a task on the concept of Modular Equation
}

\author{
"Daniela Mendes Vieira Silva"<danielamvds@yahoo.com.br> \\ "Mara Freire"<mara@uniriotec.gov.br> \\ "Daniel Lima"<danielprof20o6@gmail.com>
}

\begin{abstract}
The present article presents reflections on written productions of license holders on a task involving the concept of Modular Equation. The application methodology involved the delivery of this task and a questionnaire to graduates. Participants were invited to review the task received and to respond to the proposed questionnaire. The responses of the students were analyzed within the Toulmin Model, adapted by Biza and Nardi (2009), from this analysis we arrived at the conclusions that the pre-service teachers, in general, present direct solutions as a way to explain a question, as well as the strong presence observed of their experiences as students of basic education, with this same practice on the part of their teachers. Such perception points us to the problem of the double discontinuity observed by Felix Klein (2009). Both the direct approach as licentiates and their memory as students of the basic education of the past are tied to the very general ideas of the pedagogical approaches presented by workshop participants. Therefore, activities such as this, which allow a reflection on one's own practice, are shown as an opportunity for pedagogical/mathematical/didactic discussion and development, since they lead to self-knowledge not only of those who experience it, but also understanding on the part of those who apply it on the complex relationships between different fields of knowledge that interfere in the mathematical practice in the classroom.
\end{abstract}

Keywords: Modular Equation. Initial teacher training 


\section{Introdução}

O presente artigo tem como objetivo compreender sob a perspectiva da Matemática, da Pedagógica e Didaticamente a produção escrita de licenciandos de matemática quando analisam uma tarefa na qual é proposta uma questão dentro do tema Equação Modular. Para tanto, escolhemos uma tarefa que proponha uma questão e respostas fictícias, porém susceptíveis de ocorrer, ou seja, dentro da proposta de Biza e Nardi (2009) e também um questionário a respeito desta tarefa e aplicamos esta atividade a uma turma de licenciandos, que cursam a disciplina de Didática da Matemática.

Biza e Nardi (2007) apresentam um trabalho voltado para reflexão sobre as crenças dos professores e sua relação com a prática, onde reconhecem a discrepância evidente entre a teoria que fica fora do contexto expressa nas crenças dos professores sobre matemática e pedagogia (por estudos baseados em entrevistas) e prática real. Elas trazem uma ideia de como os professores analisam as produções dos seus alunos a partir das suas crenças e dos seus valores. Destacam ainda a importância de levar para a formação inicial dos professores situações reais, assim como os advogados fazem em suas formações. Ao propor atividades como esta, elas envolveram professores de matemática com cenários de sala de aula que são hipotéticos, mas baseados em questões de aprendizagem e ensino. E também deram destaque à utilidade e o potencial da tarefa aplicada com a seguinte estrutura:

Reflexão sobre o aprendizado/objetivos dentro de um problema matemático (e resolvê-lo);

Exame de uma falha na Solução (fictícia) de estudante;

Descrição, por escrito, de um feedback para o aluno em questão.

Como estrutura de trabalho, Biza e Nardi (2007) propõem explorar o conhecimento do assunto que o professor tem, entender suas crenças, suas motivações e ideologias, suas práticas e os tipos de feedback que eles dão aos alunos. Em suma, a tarefa permite ao professor explorar e desenvolver a sensibilidade dos licenciandos envolvidos, assim como entender um pouco mais as dificuldade e necessidades dos alunos. E com isso ampliar seu repertório de feedbacks ao aluno, para identificar o erro, investigar suas causas e compreender a oportunidade didática oferecida no momento

As referidas professoras utilizam, para a análise da interação de professores frente à tarefas propostas dentro do modelo supracitado, uma adaptação do modelo de Toulmin (1958, apud BIZA \& NARDI, 2014), que descreve a estrutura e o conteúdo semântico de um argumento em termos de seis tipos básicos de declaração: a conclusão (C) que é a afirmação que o argumento deseja convencer; os dados (D) que são as bases sobre as quais o argumento se baseia; a justificativa (W) que é o que justifica a ligação entre os dados e a conclusão e é apoiada pelo suporte (B), que apresenta mais evidências e justificativas; o qualificador modal 
(Q) que expressa graus de confiança; e, finalmente, a refutação (R) que consiste em potenciais refutações da conclusão (BIZA \& NARDI, 2014).

A análise proposta pelas professoras Biza e Nardi pretende discernir, diferenciar e discutir um espectro sobre os argumentos utilizados por professores em seu cotidiano em sala de aula. Para tanto, elas elaboraram o modelo oferecendo uma classificação de justificativas, como a de Freeman (2005), cuja adaptação feita por elas foi a seguinte (Tabela 1):

Tabela 1: Categorias de Análise

\begin{tabular}{|l|l|}
\hline $\begin{array}{l}\text { Justificativa } \\
\text { A priori }\end{array}$ & $\begin{array}{l}\text { Recorre-se a um teorema matemático ou definição (a priori-epistemológica) } \\
\text { ou a um princípio pedagógico (a priori-pedagógico). }\end{array}$ \\
\hline $\begin{array}{l}\text { Justificativa } \\
\text { Institucional }\end{array}$ & $\begin{array}{l}\text { Uma justificação de uma escolha pedagógica com base no que está sendo } \\
\text { recomendado ou requerido por uma política institucional, tal como um } \\
\text { currículo nacional ou um livro (institucional-curricular) ou se isto reflete } \\
\text { práticas padrão da comunidade matemática (institucional-epistemológica). }\end{array}$ \\
\hline $\begin{array}{l}\text { Justificativa } \\
\text { Empírica }\end{array}$ & $\begin{array}{l}\text { A citação de uma ocorrência frequente na sala de aula (de acordo com } \\
\text { experiências de ensino em matemática, empírico-profissional) ou recorrendo } \\
\text { à aprendizagem pessoal em matemática (empírico-pessoal) }\end{array}$ \\
\hline $\begin{array}{l}\text { Justificativa } \\
\text { Avaliativa }\end{array}$ & $\begin{array}{l}\text { Uma justificação de uma escolha pedagógica nos termos de um ponto de } \\
\text { vista, valor ou crença pessoal. }\end{array}$ \\
\hline
\end{tabular}

Fonte: Biza \& Nardi (2014)

O propósito da elaboração dos tipos de argumentos usados por professores no que tange à sua prática é o de demonstrar que as decisões que eles tomam cotidianamente em sala de aula não são exclusivamente fundamentadas epistemologicamente em matemática (BIZA \& NARDI, 2014).

\section{Metodologia: Produção de dados}

A primeira etapa de produção de dados consistiu em definir os sujeitos, da nossa pesquisa. Decidimos fazer uma oficina para licenciandos em matemática que não estudassem diretamente com nenhum dos autores do presente artigo. Para tanto, contactamos e pedimos a uma colega ${ }^{13}$, que ministra a disciplina Didática para o Ensino de Matemática no curso de Licenciatura em Matemática da Universidade Federal do Estado do Rio de Janeiro - UNIRIO, para que nos cedesse dois tempos de aula da sua disciplina. A disciplina Didática para o Ensino de Matemática é ofertada no quinto período do curso de Licenciatura em Matemática, ou seja, os estudantes nela matriculados já possuem uma caminhada na instituição. A segunda etapa

${ }^{13}$ A referida professora é estudante do mesmo programa de pós graduação ao qual os autores deste artigo estão vinculados. 
da produção de dados consistiu em escolher a tarefa a ser proposta aos licenciandos e o fizemos após leitura coletiva de artigos cuja temática fosse o uso das tarefas supracitadas em formações iniciais e continuadas de professores que ensinam matemática.

Figura 1: Tarefas de Álgebra

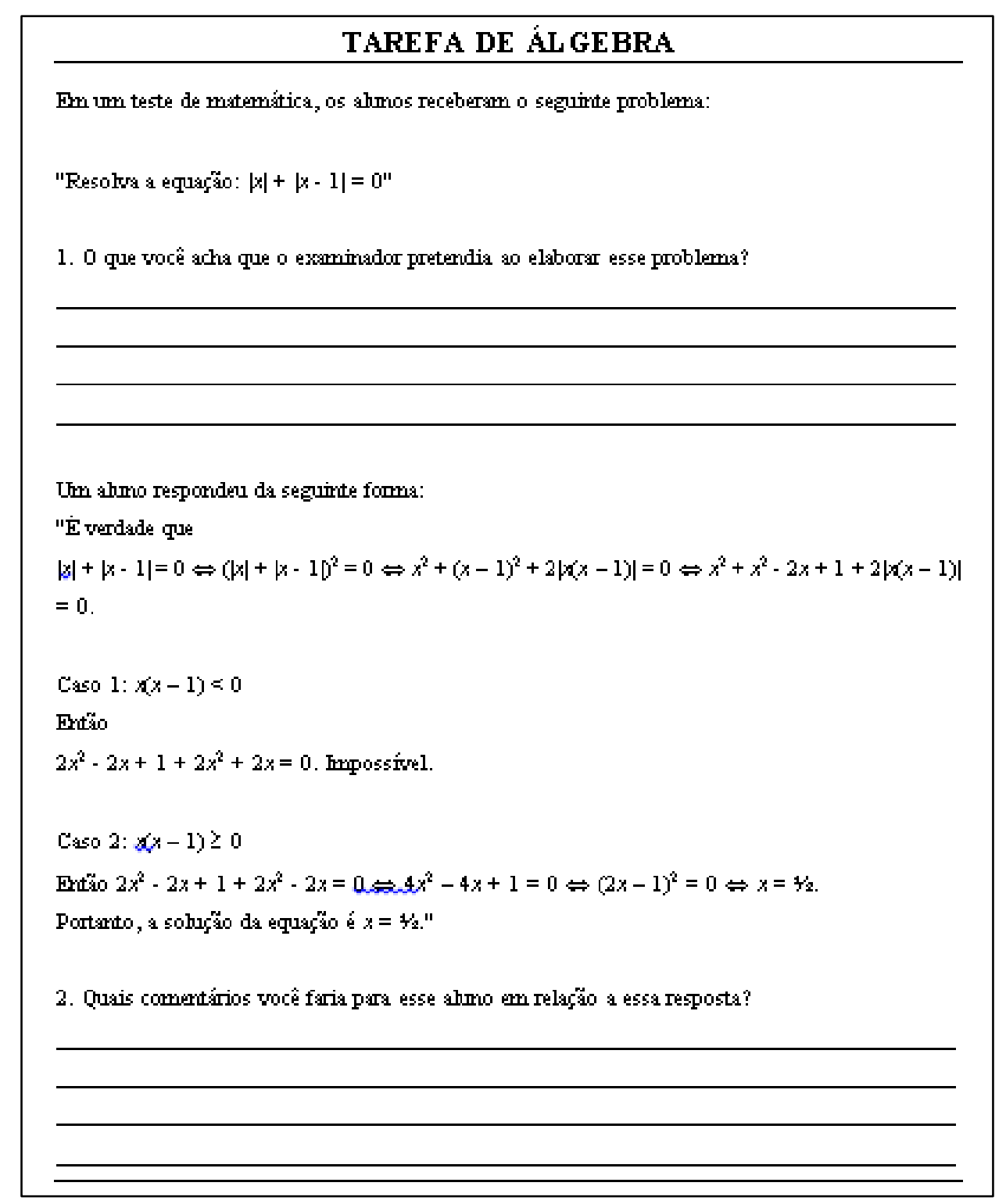

Fonte: Biza et al, 2007, p. 303, tradução Autores do texto

Para escolha da tarefa também levamos em consideração o fato de que as professoras Biza e Nardi já estiveram na UNIRIO, no ano corrente, aplicando uma tarefa envolvendo o tema Tangente aos mesmos alunos para os quais aplicaríamos a tarefa escolhida. Portanto, após deliberação do grupo de autores do presente artigo, escolhemos a tarefa apresentada no Quadro 1 para a produção de dados deste artigo. 


\section{Análise de dados}

Inicialmente, organizamos as respostas dos licenciandos por questão, agrupando-as em dois itens. Em um segundo momento, organizamos (visando fazer emergir as visões pedagógicas, matemáticas e didáticas dos participantes) cada item foi analisado a partir da classificação adaptada por Biza e Nardi (2014), relembradas adiante:

Figura 2: Classificação

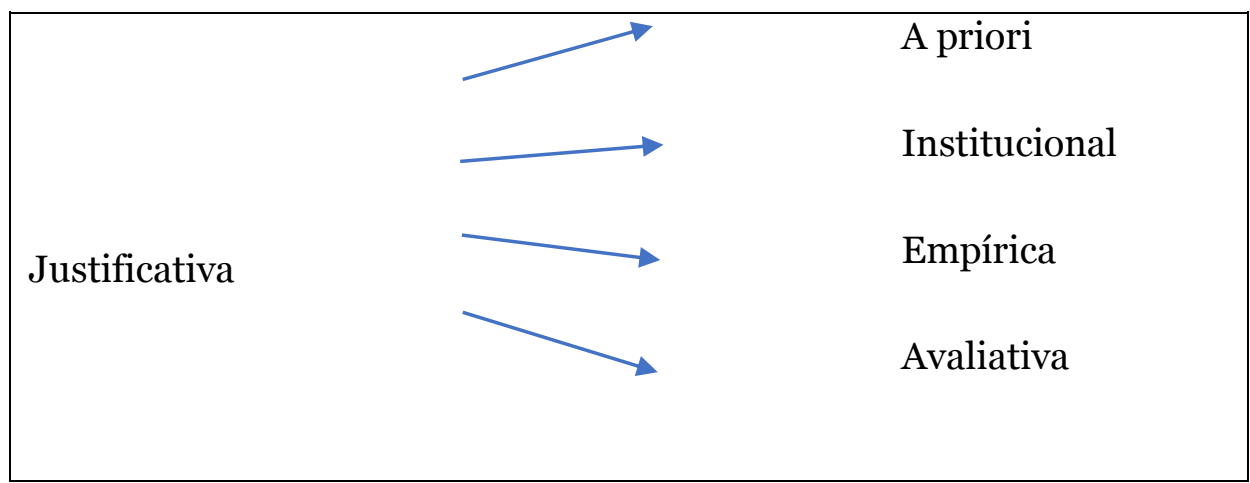

Biza e Nardi (2014)

Também fizemos recortes do diário de campo da aplicadora ${ }^{14}$ a fim de que estes nos auxiliassem a compreender não só as respostas dos licenciandos às questões propostas, mas também o contexto no qual a tarefa foi vivenciada, utilizamos o mesmo processo para as gravações, com o uso da transcrição de momentos críticos, na perspectiva de Quintaneiro e Powell (2015). A seguir descrevemos como desenvolvemos o trabalho de campo.

\section{O trabalho de Campo: Preparando}

Para o primeiro dia foram preparadas duas tarefas, uma que foi a combinada pelo grupo, e uma reserva ${ }^{15}$ (Anexo 1), um Questionário (Apêndice 1) e um Termo de Consentimento (Apêndice 2). O objetivo inicial do grupo era que durante o primeiro tempo de aula os alunos resolvessem a questão e no segundo tempo, eles expusessem suas observações sobre a atividade.

Minutos antes de iniciar a aula, as professoras se reuniram, para decidirem como seria o desenvolvimento da aula. Todo o material foi a apresentado à professora regente, que gostou muito das duas tarefas, sendo assim ela sugeriu que fossem aplicadas as duas tarefas para os licenciandos no primeiro dia e ela cederia mais dois tempos de sua aula em um segundo dia para que fizéssemos uma discussão com os licenciandos sobre as tarefas aplicadas. Como ela era a professora responsável pela turma e estava nos fazendo a gentileza de ceder quatro tempos de suas aulas do semestre para aplicarmos a atividade, houve a concordância com a

14 Elaborada pela Professora M. F.

15 Por uma questão de espaço, decidimos fazer um segundo artigo para discutir a tarefa extra em questão. ISSN 2526-2882 
sugestão da professora, uma vez que entendemos que mudanças são bem vindas e mostram uma postura dinâmica em relação ao trabalho realizado. E assim foi feito.

\section{Produzindo Dados}

Todos os participantes receberam um termo de consentimento, ao qual preencheram e assinaram. Em seguida receberam um questionário, para que respondessem perguntas referente sua vida profissional e universitária, e após responderem, devolveram e receberam a Tarefa 1 (tema: Equação Modular). Neste primeiro dia, 13 licenciandos compareceram à aula e participaram da pesquisa. Eles levaram aproximadamente 40 minutos para realizar a Tarefa, alguns licenciandos discutiram a tarefa com colegas e outros a fizeram individualmente.

Conforme os licenciandos iam finalizando a primeira tarefa, foi sendo entregue a Tarefa 2 (tema: Inequação), para que começassem a responder às questões da mesma.

No final restaram alguns minutos antes de terminar a aula, como os licenciandos ficaram muito intrigadas com a Tarefa 1, a professora regente decidiu iniciar a discussão ${ }^{16}$ sobre a mesma. No segundo dia, somente seis licenciandos compareceram. A aula teve início com a retomada da discussão sobre a Tarefa 1, percebemos que ficou claro para os licenciandos que a equação não tinha solução, porém também percebemos que eles tinham dificuldade em dar um retorno para o aluno fictício, caso o mesmo perguntasse onde estava o erro em seu desenvolvimento.

\section{Analisando os dados produzidos}

A partir da leitura dos questionários dos licenciandos verificamos que o público participante era de 5 licenciandas e 8 licenciandos, sendo 8 deles com faixa etária entre 20 e 25 anos, 2 com faixa etária entre 26 e 30 anos, 1 entre 17 e 20 anos, 1 entre 31 e 45 anos e 1 com 50 anos ou mais. Todos cursam a primeira graduação, 9 participantes já têm alguma experiência com ensino em aulas particulares, também observamos o destaque dado pelos licenciandos em foco para a mudança, visando aumentar os componentes práticos, da grade do curso de licenciatura que cursam. Apesar disso pudemos perceber pelas respostas às questões quanto ao retorno que eles deveriam dar aos alunos fictícios, tanto na Tarefa 1 quanto na Tarefa 2, que eles não têm muita noção de como direcionar os alunos, para que estes cheguem à solução correta, sem dar a mesma diretamente. Em suas falas ${ }^{17}$ os licenciandos deixaram claro que eles têm perfeita noção de que algumas percepções só ocorreram com o dia-a-dia em sala de aula, mas consideraram que esse tipo de atividade contribui muito para

${ }^{16}$ Toda discussão, com as falas dos licenciandos e professoras participantes da aplicação das tarefas foi gravada em aúdio.

17 Todas as falas encontram-se gravadas em áudio. 
formação deles. Os licenciandos aqui serão identificados por letras do alfabeto que vão de A a M.

\section{Respondendo à questão: $O$ que você acha que o examinador pretendia ao elaborar este problema?}

Em resposta à esta questão, não só as palavras, mas também as ideias de tarefas como forma de avaliação se repetem com intensidade, sendo esta a percepção de nove dos treze licenciandos consultados. Fizemos uma nuvem de palavras (figura 1) para as respostas mais frequentes à questão em foco, a qual explicita tal padrão repetitivo e focado na mensura de conhecimentos.

Figura 3: Respostas predominantes à questão 1

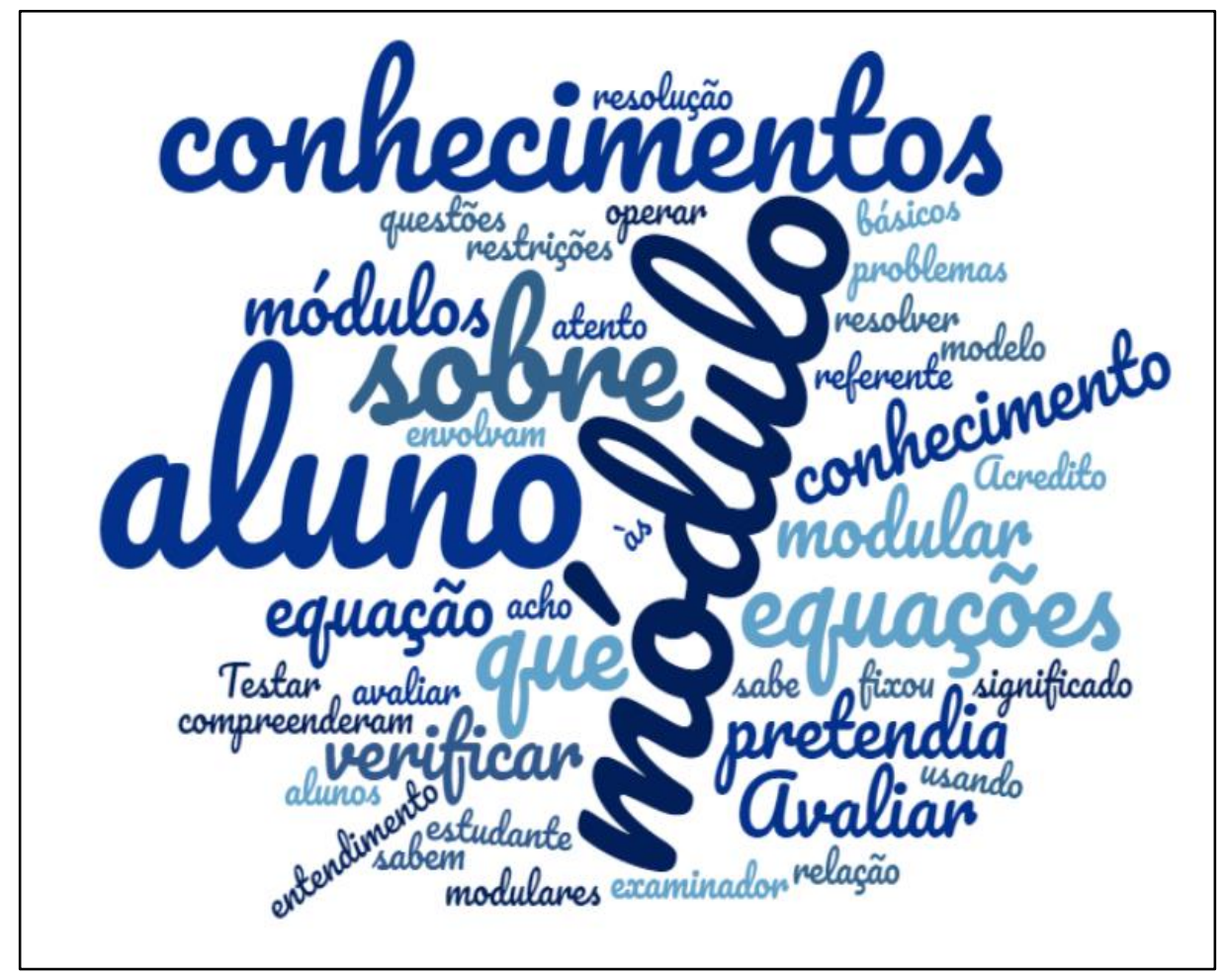

Fonte: As autoras

Adiante, discutimos, dentro das categorias de Biza e Nardi (2014), as reflexões dos participantes em relação à questão 1 .

\section{Justificativa Empírica: Empírico-Pessoal}

Aqui quase a totalidade dos licenciandos se refere à atividade proposta ao aluno fictício como tendo um objetivo avaliativo. Até mesmo as frases utilizadas por eles são praticamente idênticas, diferindo apenas em mínimos detalhes. Adiante, organizamos as ISSN 2526-2882

$$
\text { * } 94
$$


escritas dos licenciandos na tabela 2, para facilitar a nossa discussão sobre as mesmas.

Tabela 2: Justificativa Empírico-Pessoal em relação à questão 1

\begin{tabular}{|c|c|c|}
\hline Licenciando & $\begin{array}{l}\text { Resposta à questão: O que você } \\
\text { acha que o examinador pretendia } \\
\text { ao elaborar este problema? }\end{array}$ & $\begin{array}{l}\text { Comentários sobre } \quad \text { a } \\
\text { Resposta }\end{array}$ \\
\hline B & $\begin{array}{l}\text { "Testar os conhecimentos do aluno em } \\
\text { relação a modelo e resolução de } \\
\text { problemas" }\end{array}$ & \multirow{9}{*}{$\begin{array}{l}\text { O licenciando vê a atividade } \\
\text { como uma avaliação de } \\
\text { conhecimentos sobre o tema } \\
\text { equação modular }\end{array}$} \\
\hline $\mathbf{C}$ & $\begin{array}{l}\text { "Verificar o entendimento sobre } \\
\text { módulos" }\end{array}$ & \\
\hline $\mathbf{D}$ & $\begin{array}{l}\text { "Verificar se o aluno fixou os } \\
\text { conhecimentos básicos de equações com } \\
\text { módulo." }\end{array}$ & \\
\hline $\mathbf{F}$ & $\begin{array}{l}\text { "Verificar se o aluno tem conhecimentos } \\
\text { sobre equações com módulo." }\end{array}$ & \\
\hline G & $\begin{array}{l}\text { "Acredito que ele pretendia verificar se } \\
\text { os alunos compreenderam o significado } \\
\text { de módulo e se sabem operar usando } \\
\text { módulo." }\end{array}$ & \\
\hline $\mathbf{I}$ & $\begin{array}{l}\text { "Avaliar o conhecimento do aluno sobre } \\
\text { equações modulares." }\end{array}$ & \\
\hline $\mathbf{J}$ & $\begin{array}{l}\text { "Avaliar os conhecimentos do aluno } \\
\text { referente à equação modular, verificar } \\
\text { se o aluno está atento ao módulo e às } \\
\text { restrições." }\end{array}$ & \\
\hline $\mathbf{L}$ & $\begin{array}{l}\text { "Eu acho que o examinador pretendia } \\
\text { avaliar o conhecimento sobre módulo, } \\
\text { equação modular." }\end{array}$ & \\
\hline $\mathbf{M}$ & $\begin{array}{l}\text { "Verificar se o estudante sabe resolver } \\
\text { questões que envolvam módulos." }\end{array}$ & \\
\hline $\mathbf{H}$ & $\begin{array}{l}\text { "Fixar o conceito de módulo de um } \\
\text { número: que será sempre positivo." }\end{array}$ & $\begin{array}{l}\text { O licenciando vê a atividade } \\
\text { como uma oportunidade de } \\
\text { fixação de conhecimentos sobre } \\
\text { o tema equação modular }\end{array}$ \\
\hline
\end{tabular}

Fonte: Autoras do texto

Um exemplo de escritas praticamente idênticas, como supracitado, é o caso das seguintes justificativas: "Verificar se o aluno fixou os conhecimentos básicos de equações com módulo" (licenciando D), "Verificar se o aluno tem conhecimentos sobre equações com módulo" (licenciando F), "Eu acho que o examinador pretendia avaliar o conhecimento sobre módulo, equação modular (licenciando L). Este padrão de respostas se repete ao longo de toda 
a tabela.

Observamos também que as respostas dadas aqui são curtas e objetivas, o que indica pouca indecisão a respeito do tema, por parte dos participantes. A escrita consonante dos licenciandos tem identidade com a forma como sua formação acontece desde tenros anos, formação esta na qual as tarefas matemáticas, tradicionalmente, têm o papel de avaliar ou de fixar conhecimentos.

\section{Justificativa A priori: A priori-epistemológica}

Em justificativas desta categoria os autores recorrem a teoremas e definições estabelecidos pela matemática. As justificativas abaixo apresentam dentro das propriedades inerentes à definição de módulo, como validador da sua posição, como segue.

O licenciando A responde que a pretensão do examinador ao elaborar o problema sobre equação modular apresentado foi o de "Trabalhar a ideia de módulo mesmo somando números simétricos, quando estão dentro do módulo a soma nunca será negativa e só será igual a zero se ambos os lados forem zero" já o licenciando K responde à mesma pergunta afirmando que o examinador pretendia "Destacar que todo resultado em módulo é positivo, portanto a soma de dois valores positivos jamais daria o. Neste caso, nem mesmo se $\mathrm{x}=0 "$.

Em ambos os casos, observamos que esta se mostra uma opção confortável, uma vez que a responsabilidade pelo que se diz recai sobre o edifício matemático. Também, como nas respostas anteriores, não observamos indefinições e indecisões por parte dos participantes em foco.

\section{Justificativa avaliativa}

Apenas o licenciando E, fez uma escolha pedagógica a partir de seus valores e crenças pessoais em resposta à questão 1 da tarefa proposta $(O$ que você acha que o examinador pretendia ao elaborar este problema?), quando afirma que "Não tenho informações suficientes para chegar a um palpite possível. Porém, uma possibilidade plausível é a de que o professor quisesse avaliar um método de resolução de equações modais anteriormente dado em sala"

Contrariamente aos casos anteriores, podemos observar aqui a explicitação de uma posição de indecisão frente à questão, associada a um exercício, quase de imaginação para a pergunta proposta. Entretanto, esta experiência do licenciando também aponta para uma justificativa empírico-pessoal, uma vez que transparece aqui também a própria experiência formativa do participante. Isto nos indica que não existem fronteiras firmemente definidas entre as categorias.

É interessante observar aqui que nenhum dos participantes sugeriu em suas respostas 
que a tarefa apresentada a eles pudesse ser vista como uma estratégia de ensino.

\section{Respondendo à questão: Quais comentários você faria para esse aluno em relação a esta resposta?}

Adiante, apresentamos uma nuvem de palavras com o perfil de respostas que se apresentou mais frequente para o item, respostas às quais apresentaram a solução matemática da questão como alternativa de ensino da tarefa proposta (figura 2).

Figura 2: Nuvem de respostas predominantes à questão 2

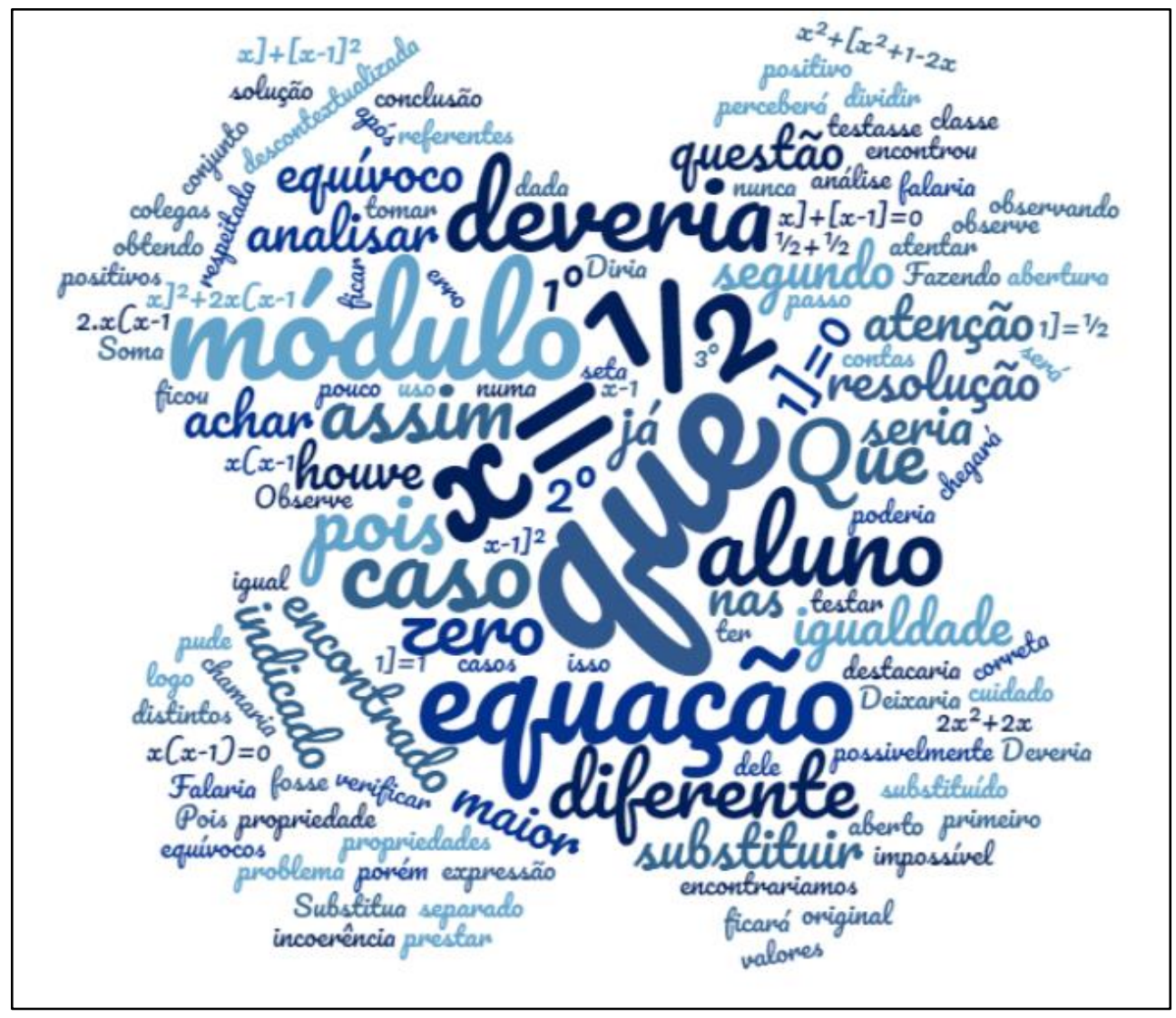

Fonte: As autoras

Adiante, discutiremos as respostas dos licenciandos nas categorias encontradas na análise das mesmas.

\section{Justificativa Institucional: Institucional-Epistemológica}

Como é possível observar, a partir da tabela adiante, tivemos respostas, corretas do ponto de vista matemático, massivamente associadas à categoria Justificativa InstitucionalEpistemológica (9 de 13). De maneira geral, estes licenciandos enfatizaram o fato de que o estudante da tarefa em foco não fez a substituição do valor encontrado para $x(x=1 / 2)$ na equação modular, o que o levaria a uma inconsistência $(1=0)$. 
Tabela 3: Justificativa Institucional-Epistemológica em relação à questão 2

\begin{tabular}{|c|c|c|}
\hline Licenciando & $\begin{array}{l}\text { Resposta à questão: Quais comentários você } \\
\text { faria para esse aluno em relação a esta } \\
\text { resposta? }\end{array}$ & $\begin{array}{l}\text { Comentários sobre a } \\
\text { resposta }\end{array}$ \\
\hline $\mathbf{A}$ & "Para prestar mais atenção nas contas" & $\begin{array}{l}\text { Demonstra aversão ao erro } \\
\text { durante a resposta aos exercícios }\end{array}$ \\
\hline $\mathbf{C}$ & $\begin{array}{l}\text { "Substitua o valor de x na equação e observe que ele } \\
\text { ficará positivo, logo será maior que o" }\end{array}$ & \multirow{8}{*}{ Faz a solução diretamente } \\
\hline $\mathbf{F}$ & $\begin{array}{l}\text { "Que no } 1^{o} \text { caso } x \text { seria } x=1 / 2 \text { e a equação não seria } \\
\text { impossivel" }\end{array}$ & \\
\hline G & $\begin{array}{l}\text { "Falaria que ele fez muito bem em dividir o } \\
\text { problema em casos distintos, porém deveria ter } \\
\text { aberto também um } 3^{\circ} \text { caso, separado do } 2^{\circ} \text {, quando } \\
x .(x-1)=\text { o. Também falaria p/ tomar cuidado com } \\
\text { o uso do "se e somente se" }\end{array}$ & \\
\hline $\mathbf{E}$ & $\begin{array}{l}\text { "10) se ele testasse o valor de " } x \text { " que ele encontrou: } \\
{[1 / 2]+[1 / 2-1]=1 / 2+1 / 2=1 \text { diferente de zero, }} \\
\text { observando uma incoerência. } 2^{0} \text { ) Soma de dois } \\
\text { valores positivos nunca é zero" }\end{array}$ & \\
\hline $\mathbf{I}$ & $\begin{array}{l}\text { "Que houve equívocos. Pois, na resolução de }([x]+[x \\
-1] 2 \text {. Deveria ser assim: } x^{2}+\left[x^{2}+1-2 x\right] . \text { No } \\
\text { primeiro caso, na abertura do módulo, deveria ficar } \\
\text { assim: }-2 . x(x-1) \text {, obtendo }-2 x^{2}+2 x \text {. E, por fim, após } \\
\text { achar o valor } x=1 / 2 \text {, deveria substituir na equação } \\
\text { original, pois } x=1 / 2 \text { não é solução. Veja: }[1 / 2]+[1 / 2- \\
1]=1 / 2+[-1 / 2]=1 / 2+1 / 2=1 \text { que é diferente de } o^{1} \text { " }\end{array}$ & \\
\hline $\mathbf{J}$ & 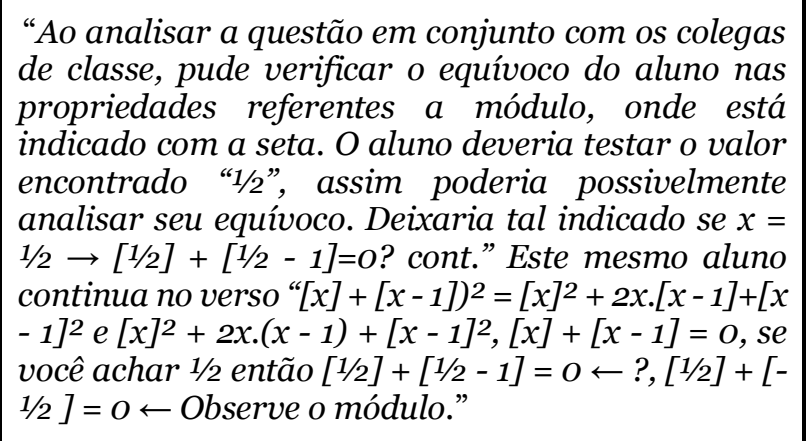 & \\
\hline $\mathbf{K}$ & $\begin{array}{l}\text { "Eu destacaria o segundo passo dele, pois não foi } \\
\text { respeitada a propriedade de módulo e também } \\
\text { chamaria atenção para a conclusão do segundo } \\
\text { caso, pois a análise a meu ver foi correta mas ficou } \\
\text { um pouco descontextualizada, já que se fosse } \\
\text { substituído na equação o valor de } x=1 / 2 \text {, não } \\
\text { encontraríamos uma igualdade } 1 / 2+[1 / 2-1]=1 \Rightarrow \\
{[x]+[x-1] \text { diferente de } 0 . "}\end{array}$ & \\
\hline $\mathbf{M}$ & $\begin{array}{l}\text { "Que houve erro na resolução da questãa, por não se } \\
\text { atentar ao módulo. Diria para o aluno pegar o valor } \\
\text { de } x=1 / 2 \text { que já foi o valor encontrado para a } \\
\text { expressão } x .(x-1) \text { maior ou igual a zero e substituir } \\
\text { na equação dada. Fazendo isso, o aluno perceberá } \\
\text { que não chegará numa igualdade." }\end{array}$ & \\
\hline
\end{tabular}

Fonte: As autoras 
É interessante destacar que as justificativas mais frequentes para o item ao tipo de ensino que tiveram na educação básica (no Brasil o ensino de matemática de maneira algorítmica, no qual os passos da solução e encontro da resposta são enumerados, é predominante). Além disso, as respostas apresentadas são feitas exclusivamente via manipulação algébrica, o que também é uma tradição do ensino do nosso país. A aplicadora da atividade faz uma interessante intervenção durante a discussão das tarefas, justamente expondo o seu raciocínio neste sentido quando afirma que: "Mas eu vejo muito o fato de que o aluno pensa que matemática é fórmula e já inicia o problema com algoritmo. ... Se tem um problema matemático, tem que ter conta, tem que ter resposta. ... só quer trabalhar com inteiro, tem medo de trabalhar com racionais, e não é assim que funciona.” (Transcrição de áudio, dia 2, minuto 42)

É importante salientar que a aplicadora também sugeriu outras possibilidades de resolução, fazendo o contraponto com o "modus operandi” do tradicional ensino de matemática brasileiro, quando afirma que: “Aqui vocês fazem o Enem, que é múltipla escolha, fazer uma prova que não precisa fazer de maneira clara, podendo fazer tanto graficamente ou algebricamente, como é esse problema. Seria válido em sala de aula?” (Transcrição de áudio, dia 1, minuto 5)

Outra das respostas que se encaixa nesta categoria é a de um licenciando que destacou a necessidade de chamar a atenção para a importância da atenção às contas, o que também nos remete a práticas de ensino que veem com maus olhos os erros na resolução de exercícios (prática muito difundida no Brasil, onde o erro, em aulas de matemática, é sempre advertido e ensinado como algo a ser evitado). É interessante observar a ocorrência de tal justificativa, uma vez que o ambiente promovido pela professora e pela aplicadora apontava na direção contrária, ou seja, na qual o erro seria visto como algo construtivo. Observe o diálogo que segue: à afirmação da aplicadora:

Licenciando: "Eu acho que ... todo raciocínio que seja lógico/coerente tem quer ser validado". Professora: "Mas quando ele olhar para a solução dele, ele vai perguntar onde está o erro?" Licenciando: "A expansão dele, tirando o módulo, a expansão daquele valor x - 1 tirando o módulo, ali tem um erro conceitual."

Professora: "Vamos fazer de novo. Observe aqui $|\mathrm{x}-1|^{2}$, é isso não é, isso aqui não é $|\mathrm{x}-1| \cdot|\mathrm{x}-1|$, o produto do módulo do $|\mathrm{x}| \cdot|\mathrm{y}|=|\mathrm{xy}|$, não é? Isso aqui também, isso aqui você pode escrever como $\mid \mathrm{x}$ $-\left.1\right|^{2}$.

Licenciando: "Mas continua com módulo, a ideia é que quando você tira do módulo, que tudo que você tira do módulo é positivo."

Professora: "Olha para o módulo de $|\mathrm{x}-1|^{2}$." ... Quem argumentou isso, ainda tem duas opções. Só que (x-1)2 é sempre positivo."

Licenciando: "Por que no final, $\mathrm{x}^{2}-2 \mathrm{x}+1$, vai dar um valor positivo."

Professora: "Por outro lado o problema não tem solução. ... duas coisas não negativas somando darem zero, a menos que elas sejam zero.... mas como o aluno chegou no meio assim, não parece algo estranho, não tem erro na conta dele."

Licenciando: "O que mais me chamou a atenção foi isso aí." 


\section{Justificativa Avaliativa}

Vemos adiante (tabela 4) as ideias de quatro licenciandos para a questão, associadas à categoria Justificativa avaliativa, categoria esta que foi contemplada para as duas perguntas propostas, o que indica a força de crenças pessoais nas decisões envolvendo o ensino de matemática.

Tabela 4: Justificativa Avaliativa em relação à questão 2

\begin{tabular}{|c|l|l|}
\hline Licenciando & $\begin{array}{l}\text { Pergunta: Quais comentários você faria } \\
\text { para esse aluno em relação a esta } \\
\text { resposta? }\end{array}$ & $\begin{array}{l}\text { Comentários sobre a } \\
\text { resposta }\end{array}$ \\
\hline $\mathbf{D}$ & $\begin{array}{l}\text { "No caso 1, não preciso dar tanta volta e colocar } \\
\text { uma complexidade na equação. Basta saber do } \\
\text { básico sobre módulo, o que acontece com uma } \\
\text { equação desse perfil e pronto." }\end{array}$ & $\begin{array}{l}\text { Critica a solução e fala de } \\
\text { maneira geral o que acredita ser } \\
\text { necessário para a resolução da } \\
\text { equação }\end{array}$ \\
\hline $\mathbf{E}$ & $\begin{array}{l}\text { "Está errado. Porém eu preciso estudar mais } \\
\text { para explicar o porquê" }\end{array}$ & $\begin{array}{l}\text { Afirma que a solução está errada, } \\
\text { mas não sabe explicar o motivo }\end{array}$ \\
\hline $\mathbf{K}$ & $\begin{array}{l}\text { "Que poderia usar o raciocínio lógico para } \\
\text { resolver questões matemáticas, antes de sair } \\
\text { aplicando regras e fórmulas. Com uma análise } \\
\text { rápida veria que é impossível, ou sem solução." }\end{array}$ & $\begin{array}{l}\text { Corrige e discute sobre o que é } \\
\text { preciso, sob o seu ponto de vista, } \\
\text { para resolver a questão }\end{array}$ \\
\hline $\mathbf{C}$ & $\begin{array}{l}\text { "Pra ele aprender a analisar o sistema antes do } \\
\text { módulo" }\end{array}$ & $\begin{array}{l}\text { Destaca, um conhecimento, a seu } \\
\text { ver, importante para a solução do } \\
\text { problema proposto }\end{array}$ \\
\hline
\end{tabular}

Fonte: As autoras

Aqui os licenciandos apresentam reflexões que parecem acontecer de si para si mesmo, uma vez que tal categoria tem como ideia fundamental a explicitação de crenças pessoais, como se os participantes estivessem "pensando em voz alta" sobre o que eles mesmo fariam baseados em seus valores.

Em nenhuma das respostas à questão 2 observamos sugestões de abordagens que levassem os alunos a alcançar o entendimento da questão, embora fosse este o ambiente da aplicação da atividade aos participantes conforme o registro apresentado no quadro 1.

\section{Considerações finais}

Ao fazer a análise das respostas dos participantes às questões, observamos que apenas as categorias denominadas por Biza e Nardi (2014) como: Justificativa: Empírico Pessoal, Avaliativa, Institucional-Epistemológica, A priori Epistemológica foram observadas nas respostas analisadas. Em uma justificativa Empírico Pessoal recorre-se a um aprendizado pessoal, na justificativa Avaliativa utiliza-se a um valor ou crença pessoal, na justificativa Institucional-Epistemológica se recorre a práticas padrão da comunidade matemática e na justificativa A Priori-Epistemológica se recorre às definições e aos teoremas da matemática. 
Portanto, vimos aqui que os licenciandos participantes retomam, a todo momento, sua própria experiência enquanto estudantes da educação básica, o que evidencia uma desconexão com a sua presença no ensino superior. Felix Klein (2009) dá a este fenômeno, o nome de dupla descontinuidade, quando afirma que:

Os jovens estudantes universitários são confrontados com problemas que nada têm a ver com as coisas que estudaram na escola e, naturalmente, esquecem-nas rapidamente. Quando, depois de completarem o curso, se tornam professores confrontados com a necessidade de ensinar a matemática elementar na forma adequada ao grau de ensino, primário ou secundário, a que se dedicam, e como não conseguem estabelecer praticamente nenhuma relação entre esta tarefa e a matemática que aprenderam na universidade, facilmente aceitam o ensino tradicional, ficando os estudos universitários como uma memória mais ou menos agradável que não tem influência na sua forma de ensinar. (KLEIN, 2009, p.1)

Portanto, atividades como esta, que permitem uma reflexão em diversos níveis sobre a própria prática, se mostram como uma oportunidade para a discussão e desenvolvimento pedagógico/matemático/didático, uma vez que elas ensejam o autoconhecimento não só daqueles que a vivenciam, mas também permite a compreensão, por parte daqueles que a aplicam, sobre as complexas relações entre diferentes campos do saber que interferem na prática matemática em sala de aula.

Como desdobramentos para o presente artigo, temos a análise dos dados da segunda tarefa aplicada, a ser feita por este grupo em um trabalho vindouro e também a possibilidade de fazermos uma roda de conversa com os licenciandos participantes na qual eles façam uma meta análise do material produzido por eles nas duas sessões.

\section{Bibliografia}

BIZA, I. N., E. ZACHARIADES, T. Teacher beliefs and the didactic contract on visualization. Edmonton: FLM Publishing Association. 2009. Using Tasks to Explore Teacher Knowledge in Situation-Specific Contexts. J Math Teacher Educ (2007) 10:301-309. DOI 10.1007/s10857-007-9043-y.

FREEMAN, JB. Systematizing Toulmin's warrants: Na epistemic approach. Argumentation, 19(3), 331-346, 2005.

KLEIN, F. Matemática Elementar de um Ponto de Vista Superior. Lisboa: Sociedade Portuguesa de matemática, 2009.

NARDI, E. BIZA, I. WATSON, S. What makes a claim an acceptable mathematical argument in the secondary classroom? A preliminary analysis of teachers' warrants in the context of an Algebra Task.Pope, S. (Ed.) Proceedings of the 8th British Congress of mathematics Education 2014. 


\section{POWELl, A. B.; QUINTANEIRO, W. O Vídeo na Pesquisa Qualitativa em Educação} matemática: Investigando pensamentos de alunos. In: Arthur Powell. (Org.). Métodos de pesquisa em educação matemática usando escrita, vídeo e internet. 1ed.São Paulo: Mercado de Letras, 2015, v. 1, p. 15-60.

\section{Biografia Resumida}

Daniela Mendes Vieira da Silva: Doutora em Ensino e História da Matemática e da Física pela UFRJ, Mestre em Educação em Ciências e Matemática pela UFRRJ, Graduada em MatemáticaLicenciatura Plena pelo CEDERJ/UFF e em Pedagogia pelo IET. Possui também atualização em Mídias na Educação pela UFRJ e Especialização em Educação Tecnológica pelo CEFET-RJ. Atualmente é professora da Universidade Castelo Branco, das Faculdades Campo Grandenses e da Secretaria de Educação do Estado do Rio de Janeiro.

Lattes: http://lattes.cnpq.br/4617961312604985

Contato:danielamvds@yahoo.com.br

Mara Jane Neves Lima Freire: Mestre em Modelagem Computacional pela Universidade do Estado do Rio de Janeiro UERJ (2003). Graduada em Licenciatura em Matemática pela Universidade do Estado do Rio de Janeiro - UERJ (2000) e atualmente é professora da Universidade Federal do Estado do Rio de Janeiro - UNIRIO.

Lattes: http://lattes.cnpq.br/8236220628868533

Contato: mara.freire@uniriotec.br

Daniel de Oliveira Lima: Possui licenciatura plena em Matemática pela Universidade do Estado do Rio de Janeiro (UERJ) e mestrado em Matemática pela Universidade Federal do Rio de Janeiro (UFRJ). Lecionou na Prefeitura do Rio de Janeiro, no Estado do Rio de Janeiro, no Colégio Pedro II e no CAP - Uerj. Atualmente é professor da Escola SESC de Ensino Médio e Diretor da ONG Instituto Bem. Hoje, pesquisa Educação Matemática Crítica, Avaliação Escolar em Matemática, ISSN 2526-2882

$$
* 102 *
$$


Aprendizagem Criativa, Metodologias Ativas e Educação

Financeira.

Lattes: http://lattes.cnpq.br/8112943098112623

Contato: danielprof2006@gmail.com 